\title{
The Cultivation of Information Infrastructures for International Trade: Stakeholder Challenges and Engagement Reasons
}

\author{
Arjan Knol' and Yao-hua Tan ${ }^{2}$ \\ ${ }^{1}$ Delft University of Technology, Department of Engineering Systems and Services, Delft, the Netherlands, \\ arjan.knol@rws.nl \\ 2 Delft University of Technology, Department of Engineering Systems and Services, Delft, the Netherlands, \\ Y.Tan@tudelft.nl
}

Received 9 May 2016; received in revised form 5 August 2017; accepted 8 August 2017

\begin{abstract}
The development of information infrastructures for international trade to improve supply chain visibility and security has gained momentum due to technological advances. An information infrastructure is a shared, open, and evolving assemblage of interlinked information systems providing distinct information technology capabilities. Examples of information infrastructures are the internet, electronic market places and music platforms. Information infrastructures can be highly beneficial as shown by the aforementioned examples, yet often fail to deliver expected benefits. This research focuses on the cultivation of information infrastructures which refers to a softer, less disruptive design approach compared to traditional design approaches in which systems are defined through specified functional requirements within strict boundaries. Drawing on different stakeholder views within a European Union project for international trade, this research provides a taxonomy of twelve cultivation challenges and four engagement reasons one can expect in the design phase of information infrastructures. Organizational theory is used to discuss underlying explanations. The paper concludes that the cultivation of an information infrastructure for international trade could be highly rewarding, yet is a challenging and long-lasting endeavor which requires multi-disciplinary expertise. Practitioners can use the insights provided by this research to increase their understanding of information infrastructure cultivation to ultimately increase adoption rates.
\end{abstract}

Keywords: Information infrastructure, International trade, Cultivation, Challenges, Issues, Interests, Supply chain 


\section{Introduction}

In an increasingly intertwined world economy, the global supply chain has become progressively complex "to a point where clear visibility is masked from those who need to know what is going on" [25], p. 3. Global supply chains are characterized by a multitude of public and private organizations such as freight forwarders, port authorities, customs, and terminal operators who collaborate to achieve the objective of transporting goods from sellers to buyers [37]. Due to technological advances a growing trend for organizations is to create external linkages and share information in order to gain increased visibility of supply chains [4]. Over the years many initiatives for the development of information infrastructures (IIs) for international trade emerged to improve supply chain visibility and security [4], [24], [25]. These Ils for international trade are specific in nature due to, for example, cross-border differences in legislation.

An II is "a shared, open, heterogeneous and evolving socio-technical system of Information Technology (IT) capabilities" [22], p. 1. Ils vary in scale, functionality and scope with examples such as the internet, electronic market places, operating systems, music platforms, mobile application platforms, movie platforms, and music platforms [22][49]. In the global supply chain Ils mainly revolve around Electronic Data Interchange (EDI) or eXtensible Markup Language (XML) networks enabling data sharing between public and private organizations (the electronic data pipelines of [25], [31].

Ils can be highly beneficial for individuals, organizations, and societies as shown by aforementioned examples such as the internet. However, many II initiatives fail to deliver expected benefits [22]. The global supply chain is no exception; in the past decades a plethora of initiatives to develop Ils for international trade have emerged to achieve collaboration [3], yet "there is a fairly widespread belief that few firms have truly capitalized on [their] potential" [35], p. 237. "Collaboration arguably has the most disappointing track record of the various supply chain management strategies introduced to date" [42], p. 24. Although individual success stories with supply chain collaboration are reported in various industries, "mainstream implementation within these industries has been much less prominent than expected" [26], p. 170. Consequently, fragmented and inaccurate supply chain information remains a problem for many private and public organizations [25], [29].

This research focuses on the cultivation of Ils which refers to a softer, less disruptive design approach compared to traditional design approaches in which systems are defined through specified functional requirements within strict boundaries. Literature presents many challenges that are encountered in the cultivation of Ils such as the bootstrap and adaptability problems of Hanseth and Lyytinen [22]. Challenges regarding Ils for international trade are also found, e.g. challenges relating to trust, power, and dependence [34]. Literature provides various reasons for engagement in Ils too such as unleashing generativity in terms of Tilson et al. [49]. Reasons to engage in Ils for international trade are mentioned as well, e.g. visibility as the holy grail [26]. However, a taxonomy of II challenges and engagement reasons from the viewpoint of different types of stakeholders in the international trade domain is missing. Insight from diverse stakeholders is important since II cultivation revolves around stakeholder mobilization [1], [4].

This paper presents a taxonomy of challenges that are encountered in the cultivation of lls for international trade as well as a taxonomy of engagement reasons in Ils for international trade. Results are obtained from a stakeholder analysis that is conducted as part of an European Union project for international trade [17]. Hence, viewpoints from different types of stakeholders are provided: supply chain businesses, governments, IT providers, and research partners. Organizational theory is used to provide underlying explanations.

On an academic level the identified challenges and engagement reasons can be used as components for a design theory for II cultivation, adding to the work of Hanseth and Lyytinen [22] and Grisot et al. [21]. A design theory is the body of knowledge that practitioners require to construct an artifact, specifying design knowledge "so that it can be communicated, justified, and developed cumulatively" [20], p. 312. On a practical level the results of this research are relevant for professionals involved in the design and cultivation of Ils.

This paper is structured as follows. First background information regarding Ils and cultivation is given. Hereafter the method of this research is presented. Then the results are included being a taxonomy of challenges and a taxonomy of engagement reasons of an II for international trade. Next organizational theory is used to provide explanations. Finally, results are discussed and conclusions and limitations are presented.

\section{Background: Information Infrastructures and Cultivation}

In the information systems research community a shift in focus "from discrete information systems towards evolving assemblages of interlinked systems" is noticed [36], p. ii. These assemblages of interlinked systems are called information infrastructures (IIs). Ils cater to generativity, trusting members to invent new uses along the way [2], [49]. "An essential characteristic of infrastructures is that they are used by many different users, with the usage evolving over time, as may the type of users" [27], p. 233. 
A central theme in the II research field is cultivation [21]. Cultivation refers to the design phase of IIs and is defined as "a softer, less disruptive approach compared to more radical methods for organizational change" [6], p. 1. Cultivation seems a proper metaphor for Ils since they evolve 'organically' over time. II cultivation introduces different complexities compared to the design of for example an administrative information system. Traditional design approaches in which systems are defined through specified functional requirements within strict boundaries are not appropriate for Ils [49]. Grisot et al. argue that "successful infrastructure innovations are based on a cultivation strategy addressing specific users' needs, usefulness, and evolutionary growth" [21], p. 197.

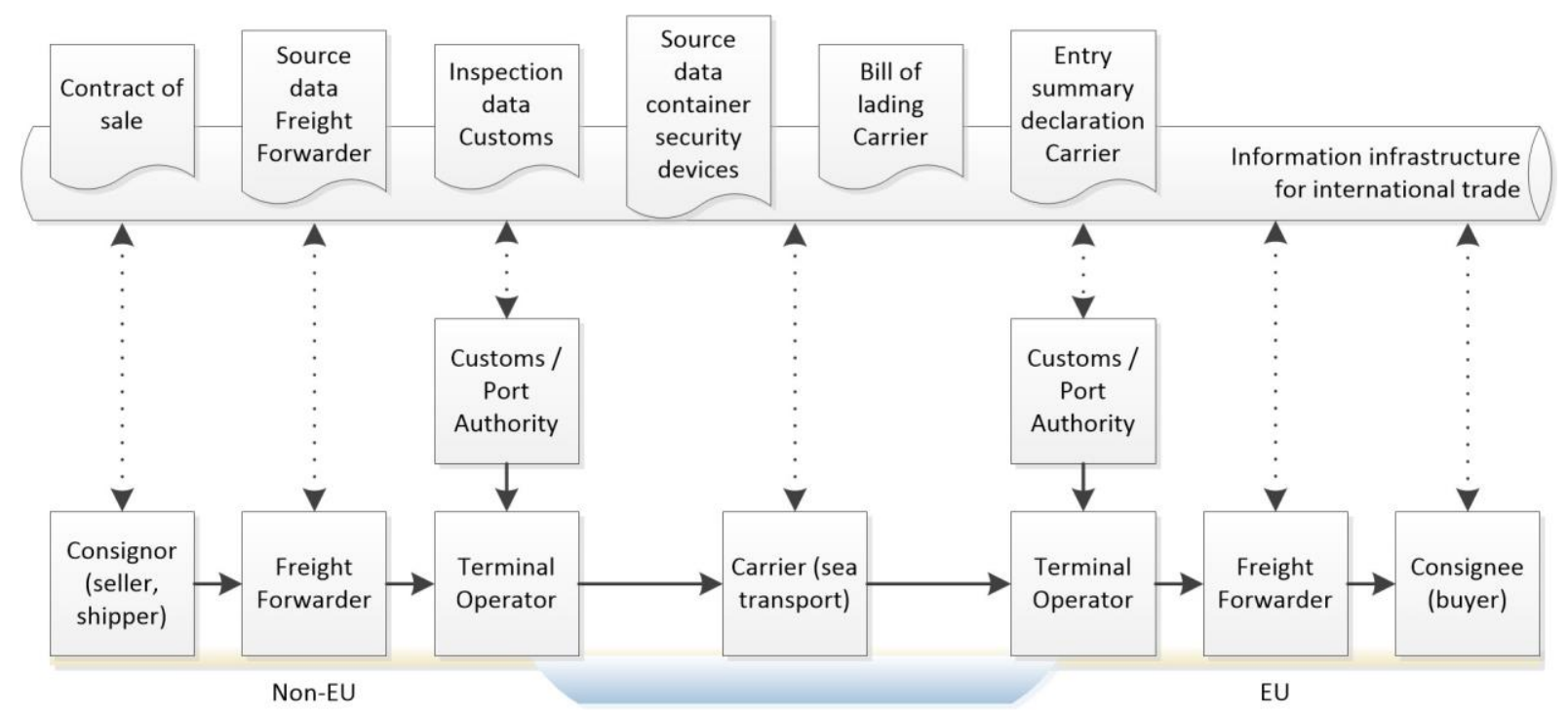

Figure 1: An II for international trade overseas (based on the data pipeline concept of [25] adapted from [31])

An II for international trade provides distinct IT capabilities to supply chain organizations with the objective to improve supply chain visibility and security [25], [4]. Figure 1 provides an example of an II for international trade overseas based on the electronic data pipeline concept of Hesketh [25]. The figure shows that (source) data from container security devices and supply chain partners can be shared within an II for international trade that is composed of interoperable IT systems used by various collaborating businesses and governments. The premise is that sharing better quality data could potentially lead to improved supply chain visibility, risk analysis, and resilience [25], [48].

\section{Method}

This interpretive research aims to provide in-depth insight into "the complex world of lived experience from the point of view of those who live it" [44], p. 118, following an inductive approach. In this research, an online questionnaire was sent to members of an EU-project for international trade who were involved in the cultivation of Ils. 20 members responded (see Table 1), based on which a taxonomy of challenges and engagement reasons was derived.

Taxonomies originated in biology and deal with "the classification of living things" [8], p. 17. This paper presents corporate taxonomies regarding an II for international trade, which "may be viewed as a conceptual map [...] that can assist every business activity" [46], p. 34, categorizing phenomena of interest for organizations [19], p. 619.

Following the work of Knol, Janssen and Sol [30], Rowley [41], and Pan [38], the questionnaire was structured as follows. First, a number of demographic questions were asked with the objective to identify the stakeholder types. Hereafter seven aspects of the II for international trade were presented that were key in the EU project: 1) security technologies such as container security devices, 2) interoperability by connecting information systems, 3) supply chain visibility, 4) supply chain resilience, 5) supply chain risk management, 6) system based supervision, and 7) coordinated border management. For each aspect the stakeholders were asked to: 1) describe how the aspect could be applied in the supply chain trade lanes they were involved in, and 2) fill in their interests, concerns, and levels of enthusiasm (ranging from high resistance to very enthusiastic).

The taxonomy of challenges in this paper presents 12 challenges derived from 105 concerns expressed by 18 stakeholders. The taxonomy of engagement reasons presents 4 reasons derived from 107 interests expressed by 19 stakeholders. In this paper each challenge and engagement reason is explained and related to the II and supply chain management literature. In addition, underlying explanations are presented using organizational theory and several insights are discussed. 
Table 1: Diverse stakeholders provided various II concerns and interests

\begin{tabular}{|l|c|l|l|}
\hline Stakeholder type & N & Based in & Results \\
\hline Business & 8 & $\begin{array}{l}\text { United Kingdom, Belgium, the } \\
\text { Netherlands, Italy, Switzerland, and } \\
\text { Spain }\end{array}$ & $\begin{array}{l}\text { 6 out of 8 supply chain businesses } \\
\text { provided concerns, all 8 provided } \\
\text { interests }\end{array}$ \\
\hline Government & 5 & United Kingdom and the Netherlands & $\begin{array}{l}\text { All government stakeholders provided } \\
\text { concerns as well as interests }\end{array}$ \\
\hline IT provider & 5 & $\begin{array}{l}\text { Spain, Cyprus, Canada, and the } \\
\text { Netherlands }\end{array}$ & $\begin{array}{l}\text { All IT providers provided concerns as } \\
\text { well as interests }\end{array}$ \\
\hline Advisor & 2 & The Netherlands and Germany & $\begin{array}{l}\text { All advisors provided concerns, 1 out of } \\
\text { 2 provided interests }\end{array}$ \\
\hline
\end{tabular}

\section{Taxonomy of II Cultivation Challenges}

This section presents various challenges regarding the cultivation of an II for international trade that are derived from stakeholder concerns. First the taxonomy is presented in Table 2. Hereafter each challenge is explained including exemplary stakeholder quotations.

Table 2: Taxonomy of challenges regarding the cultivation of an II for international trade

\begin{tabular}{|c|c|c|c|c|c|c|}
\hline Category & Challenge & Explanation & $\mathrm{B}^{*}$ & $\mathrm{G}$ & IT & $\mathrm{A}$ \\
\hline Trust & $\begin{array}{l}\text { Stakeholder } \\
\text { mobilization }\end{array}$ & $\begin{array}{l}\text { Resistance (e.g. due to sharing of commercially } \\
\text { sensitive data), collaboration, trust }\end{array}$ & 3 & 4 & 4 & 1 \\
\hline Governance & $\begin{array}{l}\text { Governance } \\
\text { agreements }\end{array}$ & $\begin{array}{l}\text { Agree on governance aspects such as data ownership, } \\
\text { data sharing, data storage, mandatory use, legal } \\
\text { repercussions in case of misuse, responsibilities, } \\
\text { starting from scratch or building on existing systems, } \\
\text { and who is paying for what }\end{array}$ & 3 & 2 & 2 & 2 \\
\hline Financial & Costs & $\begin{array}{l}\text { Investment costs, operational costs, return on } \\
\text { investments, business model }\end{array}$ & 3 & 4 & 3 & 2 \\
\hline Process & $\begin{array}{l}\text { Process } \\
\text { reengineering }\end{array}$ & $\begin{array}{l}\text { The redesign of existing business / governmental } \\
\text { processes to achieve efficient and effective transactions } \\
\text { using the II }\end{array}$ & 3 & 2 & 3 & 2 \\
\hline $\begin{array}{l}\text { Decision } \\
\text { support and } \\
\text { Risk } \\
\text { Management }\end{array}$ & $\begin{array}{l}\text { Complex risk } \\
\text { analysis }\end{array}$ & $\begin{array}{l}\text { How to use the data within the II for effective risk } \\
\text { analysis and decision making }\end{array}$ & 2 & 1 & 2 & 1 \\
\hline \multirow[t]{3}{*}{ Technology } & $\begin{array}{l}\text { Interoperability, } \\
\text { data standards }\end{array}$ & $\begin{array}{l}\text { Connect information systems within the II using specified } \\
\text { data standards }\end{array}$ & 2 & 1 & 3 & \\
\hline & Connectivity & Difficulties in connecting to the II & 1 & & 2 & \\
\hline & Software & $\begin{array}{l}\text { Difficulties in creating easy-to-use and usable software } \\
\text { (e.g. dashboards) based on data within the II }\end{array}$ & 1 & & & \\
\hline \multirow[t]{2}{*}{ Data } & Data quality & $\begin{array}{l}\text { The quality of data that is shared within the II in terms of } \\
\text { accuracy and reliability }\end{array}$ & 1 & & & 1 \\
\hline & $\begin{array}{l}\text { Data } \\
\text { redundancy }\end{array}$ & $\begin{array}{l}\text { By combining multiple data sources within an II there is } \\
\text { a risk of data redundancy. Redundant data could be } \\
\text { useful however, e.g. enabling cross-verification to } \\
\text { improve risk analysis }\end{array}$ & & 1 & & \\
\hline Legal & Legal burdens & $\begin{array}{l}\text { Legal hurdles such as public-private data sharing and } \\
\text { EU inspection rates }\end{array}$ & & 1 & 1 & 1 \\
\hline Security & $\begin{array}{l}\text { Criminal } \\
\text { exploitation }\end{array}$ & $\begin{array}{l}\text { How to avoid criminal exploitation when sensitive data } \\
\text { within the II could be hacked and risk analysis is based } \\
\text { on II data }\end{array}$ & 2 & 1 & & 1 \\
\hline
\end{tabular}

\subsection{Stakeholder Mobilization}

A stakeholder is defined as an individual or group who can affect or is affected by an organizational goal which for this research is the cultivation of an II [17], [43]. "Simply put, a stakeholder has an interest (stake) in a goal" [30], p. 2467. Stakeholder mobilization is recognized as a core challenge for II cultivation and revolves around "organizing, mobilizing and coordinating multiple independent stakeholders" [1], p. 164. Stakeholder mobilization is about dealing with resistance and achieving collaboration and trust among a diverse and evolving set of stakeholders who are partaking in the cultivation of Ils. Matopolous et al. [34] mention that trust is a critical element for the establishment and maintenance of supply chain collaboration. 
As shown in Table 2, stakeholder mobilization is a frequently mentioned challenge by the four stakeholder groups, explained with quotations such as: private and public entities need to find ways to cooperate in a much better way to shield the common interest on supply chain security (government stakeholder) and the tricky part of the discussion concerns the content i.e. organized trust and mutual respect for each other's interests [which] mainly concerns not a technological standard (government stakeholder).

\subsection{Governance Agreements}

"Governance refers to the solutions that individuals and organizations devise for problems of coordination [and is] commonly reserved for the more strategic choices" [33], p. 164. A necessity to make governance agreements regarding the II for international trade is mentioned frequently by the diverse stakeholders who filled in the online questionnaire.

The stakeholders referred to a number of governance aspects regarding an II for international trade: data ownership, data sharing, data storage, mandatory use, legal repercussions in case of misuse, responsibilities, starting from scratch or building on existing systems, and who is paying for what. Exemplary quotations are: define separated responsibilities and clear lines of demarcation (government stakeholder), which information am I sharing? With whom? [...] Who can access the data? (IT provider), opportunistic behavior; it is nice to trust a company that is part of [a] trusted trade-lane, but the stakes are high [...] what happens in case of misuse of trust? What are the legal repercussions? (advisor), and an important issue is who should pay for the application of these new technologies (business stakeholder).

\subsection{Costs}

Financial concerns regarding an II for international trade were frequently expressed by the stakeholders. This aspect is also recognized by Henningsson et al: "barriers to overcome [...] includes the total cost of IT investments, but perhaps more significantly there is the inequitable distribution of cost vs. return on investments across partners of varying sizes" [24], p. 13.

The stakeholders expressed their financial concerns with quotations such as: the most important concern is the cost of the technologies especially in relation with low value goods (business stakeholder), total amount of investments [...] balance in costs and benefits (government stakeholder), and increasing costs of communication (IT provider). In addition, business models for stakeholders partaking in the II for international trade were mentioned: identify the right business model process to enable sustainable information sharing (IT provider) and appropriate business models for both the ones providing the visibility service and the one receiving the service (IT provider).

\subsection{Process Reengineering}

Business process reengineering or business process management "includes methods, techniques, and tools to support the design, enactment, management, and analysis of operational business processes" [51], p. 1. Davenport and Stoddard argue that business process reengineering is challenging: "expectations frequently go unfulfilled, and frustrations that we must be doing it the wrong way contribute to the failure of many promising reengineering efforts" [12], p. 121.

Process reengineering challenges are recognized in the international trade domain as well. Redesigning business and governmental processes to achieve efficient and effective transactions using an II for international trade seems easier said than done. A stakeholder mentioned: our main concern is about the time we need for having all this done [...] too many [...] different routines have to be aligned to achieve the main goal (IT provider). Other stakeholders expressed process reengineering concerns regarding the usage of smart technologies such as container security devices: disturbance of logistics processes (advisor), administrative and logistics burdens (repositioning, finding them in the ports etc.) (business stakeholder), and reverse logistics [...] practical issues (IT provider).

\subsection{Complex Risk Analysis}

Increased availability of data in the II for international trade opens up possibilities for stakeholders to improve their risk analysis and decision making processes. A challenge is, however, that it is not clear how to use the data within the II for effective risk analysis and decision making.

The stakeholders expressed this challenge as follows: we have yet to prove the mechanism for taking data from the pipelines and into the regulatory agencies (government stakeholder), [risk analysis] can become very complex, not all elements might be available to generate the alerts (IT provider), and [our] main concern is to identify and weigh properly the risks always meeting a compromise solution (business stakeholder). 


\subsection{Interoperability, Data Standards}

Interoperability is defined as "the ability for two systems to understand one another and to use functionality of one another [and] is considered as significant if the interactions can take place at least on three different levels: data, services and processes" [9], p. 648. Examples of data standards that enable interoperability are EDI and XML [40].

Ils for international trade are envisioned as "evolving assemblages of interlinked systems" [36], p. ii. Establishing these interlinked assemblages using specified data standards is challenging, however. The stakeholders expressed a number of concerns relating to interoperability and data standards such as: management systems have to be connected with each other so organizations have all data available (IT provider), close technology not interoperable utilized (business stakeholder), different standards (government stakeholder), too many interconnections (business stakeholder), and connection with the ecosystem [...] how can I connect/disconnect? (IT provider).

\subsection{Connectivity}

Connectivity to an II for international trade can pose difficulties. A stakeholder mentioned that internet has to be available on the control site for enforcement agencies or they have to contact a colleague who has access to the system (IT provider). In addition, connectivity problems can occur when sensors break down: immediate information when data sensor is broken (IT provider).

\subsection{Software}

Data within an II for international trade can be presented and visualized using software (programs) such as dashboards. However, creating easy-to-use dashboards showing useful information [13] can be challenging as expressed by a stakeholder: is access by a dashboard possible? (government stakeholder).

\subsection{Data Quality}

Data that is shared within an II for international trade needs to be of sufficient quality to enable for example meaningful risk analysis [29]. Dimensions of data quality include among others accuracy, reliability, completeness, consistency, and timeliness [52]. A stakeholder expressed the following regarding data quality: a very important concern is accuracy and reliability of the data shared (business stakeholder).

\subsection{Data Redundancy}

By combining multiple data sources within an II for international trade there is a risk of data redundancy (duplications) as expressed by a stakeholder: risk of data redundancy (government stakeholder). It could be debated whether data redundancy is a challenge, however. Using multiple data sources could, for example, enable crossverification and improve the quality of risk analysis. Jüttner and Maklan mention that redundancy is used as a strategy "aimed at preventing disruptions of supply chain operations through redundant tangible (e.g. transport or production capacities) or intangible (e.g. processes, skills) resources" [28], p. 251.

\subsection{Legal Burdens}

Legislation can pose problems in the cultivation of an II for international trade in that they can obstruct changes in work practices. For example, phytosanitary agencies have to adhere to a minimum amount of physical inspections which means that improved risk analysis based on data within an II for international trade does not necessarily mean a reduction of inspections for them: from the first hearings, it is clear that the phytosanitary agencies have much less room to maneuver than Dutch customs do. They must follow EU policies regarding inspection rates. (advisor). Other stakeholders expressed the following regarding legal burdens: legal barriers have to be identified and overcome (government stakeholder) and different governments have different laws and interpretations of the law (IT provider).

\subsection{Criminal Exploitation}

Data is prone to being hacked when all data, including commercially sensitive data, is available within an II. This could for example lead to supply chain flow counterfeit. The stakeholders mentioned the following concerns related to security: privacy protection (government stakeholder), interoperability could create privacy concerns (business stakeholder), risks of incidents such as flow counterfeit, piracy, smuggling (business stakeholder), and resilience against cyberattacks must be ensured (advisor). Furthermore, a stakeholder pointed out that tampering with security technologies such as container security devices opens up ways for criminal exploitation: tampering in intermodal business (business stakeholder). Another stakeholder stated that risk analysis solely based on II data does not suffice: criminal activities still need to be detected (advisor). 


\subsection{Synthesis of Findings}

In short, the results of this research clarify that II cultivation in the international trade domain is challenging. Managers need to account for diverse stakeholder considerations, evolutionary growth versus governance agreements, return on investments and business models, process reengineering, technological aspects, legal aspects, and security aspects. A multidisciplinary approach is therefore recommended to account for the diverse socio-technical challenges identified in this research.

\section{Taxonomy of II Reasons for Engagement}

This section presents a number of reasons for engagement in an II for international trade as expressed by various stakeholders. First the taxonomy is presented in Table 3. Hereafter each interest is explained including exemplary stakeholder quotations.

Table 3: Taxonomy of reasons for engagement in an II for international trade

\begin{tabular}{|l|l|l|l|l|l|l|}
\hline Category & Challenge & Explanation & $B^{*}$ & $G$ & IT & A \\
\hline Data & $\begin{array}{l}\text { Improved data } \\
\text { availability }\end{array}$ & $\begin{array}{l}\text { Availability of better quality (real time, source) supply } \\
\text { chain data within the II }\end{array}$ & 3 & 1 & 1 & \\
\hline Visibility & $\begin{array}{l}\text { Improved } \\
\text { supply chain } \\
\text { visibility }\end{array}$ & $\begin{array}{l}\text { The extent to which stakeholders within a supply chain } \\
\text { have access to or share information within the II to better } \\
\text { achieve their goals (efficiency, effectiveness) }\end{array}$ & 8 & 1 & 4 & 1 \\
\hline Security & $\begin{array}{l}\text { Improved risk } \\
\text { analysis and } \\
\text { security }\end{array}$ & $\begin{array}{l}\text { Enhanced risk analysis by governments based on data } \\
\text { shared within the II which could increase security and } \\
\text { lead to a lower number of inspections for compliant } \\
\text { businesses (trusted traders) }\end{array}$ & 8 & 5 & 5 & 1 \\
\hline Resilience & $\begin{array}{l}\text { Improved SC } \\
\text { resilience }\end{array}$ & $\begin{array}{l}\text { An improved ability of a supply chain to recover from } \\
\text { unavoidable risk events / disturbances using data that is } \\
\text { shared within the II }\end{array}$ & 3 & 2 \\
\hline
\end{tabular}

\subsection{Improved Data Availability}

Improved availability of data shared within an II is mentioned by several stakeholders as a reason for engagement. Quotations include: data capture at the source and input to the pipeline for data exchange between businesses, port community systems and customs organizations (business stakeholder), interest is in better quality, real time data (government stakeholder), and data platform - exchange of data between various operators in the transport chain and authorities (business stakeholder). The real time data aspect is in line with the timeliness dimension of data quality of Wand and Wang [52].

\subsection{Improved Supply Chain Visibility}

Visibility refers to the capability of "being perceived by the eye or mind" [28], p. 248. Supply chain visibility is defined as "the extent to which actors within a supply chain have access to or share information which they consider as key or useful to their operations and which they consider will be of mutual benefit" [4], p. 1230. More specifically, supply chain visibility is "the identity, location and status of entities transiting the supply chain, captured in timely messages about events, along with the planned and actual dates/times for these events" [16], p. 182. The concept is considered as a holy grail [26], for example for avoiding bullwhip effects [32]-[10]. Supply chain visibility can be the outcome of information sharing within an II for international trade and "could lead to an improved operational performance of a supply chain" [4], p. 1230. Supply chain visibility as the effect of information sharing within an II could improve an organization's efficiency and effectiveness (doing things right and doing the right things in terms of [15]).

Stakeholder quotations include: using the pipeline to capture and display the data to businesses and customs with accurate data on the whereabouts of containers in the supply chain, transshipments and alerts to enhance visibility (business stakeholder), supply chain visibility from data pipelines will allow the relevant supply chain parties to have access to relevant information which will help them to attain their business objectives (government stakeholder), more certainty about status and inspections (advisor), combining carrier, forwarder and other data sources provides good visibility (IT provider), and our main interest is to count on a whole dashboard system which can give us a wide visibility and decision power (business stakeholder). 


\subsection{Improved Risk Analysis and Security}

Increased availability of data in the II for international trade opens up possibilities for stakeholders to improve their risk analysis and decision making processes. Tan et al. [48] introduced the piggybacking principle which proposes that governmental inspection authorities re-use business supply chain source data for risk analysis. Improved risk analysis could lead to increased security of supply chains as well as a decrease of physical inspections by customs for compliant businesses who can show they are in control of their business ([trusted traders in terms of [24]).

Stakeholder quotations include: better quality data from commercial data pipelines allows customs and border agencies to assess risks earlier and to a higher standard (government stakeholder), the pipeline will see a reduction in supply chain disturbances, for example physical container inspection at the border could be dramatically reduced with visibility and accuracy of the data describing what is in the box and data on trusted traders, allowing for containers to be put through without inspection (business stakeholder), Dutch customs can recognize the efforts of their Colombian / Kenyan counterparts [...] in principle the number of inspections on the Dutch side could be reduced (advisor), early warning/detection of criminal activity (government stakeholder). Some stakeholders referred to the aforementioned trusted trader concept: better quality data enhances compliance and risk assessment and the relationship between importerlexporter and customs [...] the identification of complaint companies allows them to be de-risked and more effort placed on the non-compliant (government stakeholder) and shift the focus of the law enforcement to the exceptions to the rule (government stakeholder).

\subsection{Improved Supply Chain Resilience}

"The core concept of resilience is related to the ability of a system to return to a stable state after disruption" [47], p. 11. Jüttner and Maklan [28] provide four resilience capabilities: flexibility (sense change and adapt to change), velocity (the speed of adaptation), visibility (know what is going on, picking up the right signals), and collaboration (stakeholders willingness to share information). The sharing of high quality supply chain data within an II could enhance these four capabilities and as such improve supply chain resilience.

Several stakeholders provided quotations that relate to their interest in supply chain resilience using the II for international trade, among others being: supply chain resilience is very important to quickly recover to common situation from disruptions (business stakeholder) and having data from the tracking and tracing technologies will result in having useful information that allows operators to take immediate actions when an abnormal event occurs (IT provider).

\subsection{Synthesis of Findings}

In summary, the results of this research show that many stakeholders have an interest in an II for international trade. Their reasons for engagement are founded in the availability of better quality supply chain data to improve visibility, risk analysis and security, as well as resilience.

\section{Discussion}

This section discusses how the II cultivation challenges and engagement reasons relate to organizational theory. In addition a paradox of control and a decreased resource dependence engagement reason are discussed.

\subsection{Organizational Theory}

Ulrich and Barney [50] distinguish between a resource dependence, efficiency, and population perspective which relate to the II cultivation challenges and engagement reasons that are identified in this research.

First, in the resource dependence perspective organizations aim to maximize their power by "altering their structure and patterns of behavior to acquire and maintain needed external resources" [50], p. 472. This relates to the resource dependency theory of Pfeffer and Salancik [39] viewing organizations as coalitions that aim to decrease their resource dependence on other organizations and increase the dependence of others on them [11]-[18]. In addition this perspective relates to the stakeholder theory of Freeman [17] which states that stakeholder support is required "to create and sustain winning coalitions" [7], p. 23. The challenge to mobilize stakeholders in the cultivation of an II, which is about dealing with resistance and achieving collaboration and trust, relates to the resource dependence perspective. II cultivation can distort existing power and dependence relationships which is why stakeholders can resist cultivation. For example, a trader can resist cultivation, because sharing commercially sensitive data within an II can decrease the resource dependence of others on them. And an IT provider who will maintain an II for international trade could support cultivation due to an increase of the resource dependence of others on them. 
Second, in the efficiency perspective "successful organizations are those that are able to manage their transactions efficiently" [50], p. 473. A related theory is the transaction cost theory of Williamson [53] which proposes that organizations aim to minimize their transaction and production costs to achieve efficiency. The efficiency perspective is directly reflected in the cost challenge identified in this research in which a stakeholder pointed out that the usage of container security devices within an II will increase costs of communication (IT provider). Many other identified challenges in this research also relate to the efficiency perspective since they predominantly revolve around difficulties in achieving efficiency using an II (doing things right in terms of [15]). The challenges of process reengineering, complex risk analysis, interoperability and data standards, connectivity, software, data quality, legal burdens, and criminal exploitation all pose hurdles to achieve efficiency using an II. In addition, all engagement reasons that are identified in this research predominantly relate to the efficiency perspective. Improved data availability, supply chain visibility, risk analysis and security, and supply chain resilience support a more efficient way of working using an II for international trade.

Third, "if power maximization defines organizational success in the resource dependence perspective and if efficiency plays the same role for the efficiency perspective, then organizational success in the population perspective can be defined as survival" [50], p. 474. An aspect to consider when talking about survival is luck. "Because the selection pressures in an environment are essentially unpredictable and the strategies of successful firms are only partially subject to imitation, firms and populations of firms that are selected for may, in fact, simply be lucky" [50], p. 475. This relates to contingency theory which states that organizational survival is dependent (contingent) on an organization's environment and that adaptation to the environment is essential [14]-[45]. In addition, the cultivation and evolutionary growth aspects of IIs relate to the population perspective. It can be argued that the governance challenges identified in this research predominantly relate to the population perspective, since agreements on how to govern an II for international trade are necessary to allow for II cultivation and evolutionary growth. Further, the interoperability and data standards challenge relates to the population perspective in that the challenge can be caused by non-interoperable legacy systems that have emerged 'organically' over the years. Legacy systems are "large software systems that we don't know how to cope with but that are vital to our organization [and they are typically] written in assembly or an early version of a third-generation language" [5], p. 19. It is a challenge to achieve interoperability among legacy systems, since they usually do not adhere to modern data standards. Finally, it could also be argued that the engagement reasons identified in this research relate to the population perspective, since improved supply chain visibility, resilience, and risk analysis and security using an II for international trade could lead to long-term survival for organizations.

To conclude, the three theoretical perspectives of Ulrich and Barney [50] provide deeper insight into why challenges are encountered in the cultivation of Ils for international trade and why stakeholders engage in these Ils. The resource dependence perspective explains that resistance is posed during II cultivation due to distorted power and dependence relationships, therefore relating to the stakeholder mobilization challenge. The efficiency perspective explains that organizations aim to minimize production and transaction costs and therefore relates to challenges such as costs and process reengineering as well as engagement reasons such as improved visibility and risk analysis. The population perspective explains that organizations aim for long-term survival in changing environments which relates to the cultivation and evolutionary growth aspects of Ils. The population perspective for example relates to challenges in making governance agreements to allow for cultivation.

\subsection{Paradox of Control}

The identified challenge to make II governance agreements on aspects such as data ownership, data sharing, mandatory usage, and legal repercussions in case of misuse seems to contradict with allowing for II cultivation that will evolve 'organically' over time. The question is whether the managerial quest for control and governance in order to avoid chaos will foster or block II cultivation. This relates to the paradox of control phenomenon of Tilson et al. which is explained by "opposing logics around centralized and distributed control [resulting in a] paradox of both more and less control" [49], p. 754. Aanestad and Jensen [1] argue that even though a vision is necessary to kickstart an II transformation process, II cultivation requires an incremental and iterative process that unfolds over many years.

Henningsson et al. state that regarding the cultivation of an II for international trade "a significant part of the infrastructural change process involved organizational rather than technological issues" [24], p. 12. Aanestad and Jensen argue that "in realizing nation-wide Ils for healthcare [...] large-scale and long-term stakeholder mobilization is a core challenge" [1], p. 174. These observations are in line with the results of this research showing that stakeholder mobilization is key. A sole focus on mobilizing stakeholders and dealing with distorted power and resource dependence relationships when cultivating Ils does not seem enough, however. This research shows that financial aspects, governance agreements, and process reengineering are core challenges as well.

\subsection{Resource Dependence}

The core reasons to engage in Ils for international trade are improved supply chain visibility, risk analysis, and security which is in line with the literature (e.g. [25], [26]). Following the resource dependence perspective, an interesting aspect is that improved power or a decreased dependence on others is not mentioned as an engagement 
reason in an II for international trade by the stakeholders. II cultivation triggers distortion of existing power and resource dependence relationships which could be advantageous for some as well.

\section{Conclusions and Future Research}

To conclude, the cultivation of an II for international trade is a challenging and long-lasting endeavor which requires multi-disciplinary expertise and an incremental and iterative cultivation strategy. Key II cultivation challenges to account for are stakeholder mobilization, costs, governance agreements, and process reengineering. Successful cultivation of an II for international trade could be highly rewarding, however, as shown by the key engagement reasons identified in this research which revolve around improved supply chain visibility, risk analysis, and security. Practitioners can use the insights provided by this research to increase their understanding of II cultivation to ultimately increase the adoption rate of Ils.

The identified challenges and engagement reasons can be used as components for a design theory for II cultivation. For future research additional case study material can be useful, since the results of this research are based on limited material provided by 20 respondents. Future research can focus on taking a closer look at individual II cultivation challenges and engagement reasons and related theoretical perspectives. In addition, future research can be dedicated to generalizability, investigating which challenges and engagement reasons are encountered in II cultivation outside the international trade domain. Finally, future research could focus on cultural differences which do not appear as a challenge in this paper, although some of the assertions made (e.g. in principle the number of inspections on the Dutch side could be reduced) could depend on cultural or context-specific issues associated with II partners.

\section{References}

[1] M. Aanestad and T.B. Jensen, Building Nation-wide Information Infrastructures in Healthcare through Modular Implementation Strategies. The Journal of Strategic Information Systems. vol. 20, no. 2, pp. 161-176, 2011.

[2] M. Avital and D. Te'Eni, From Generative Fit to Generative Capacity: Exploring an Emerging Dimension of Information Systems Design and Task Performance. Information Systems Journal. vol. 19, no. 4, pp. 345-367, 2009.

[3] M. Barratt, Positioning the Role of Collaborative Planning in Grocery Supply Chains. The International Journal of Logistics Management. vol. 14, no. 2, pp. 53-66, 2003.

[4] M. Barratt and A. Oke, Antecedents of Supply Chain Visibility in Retail Supply Chains: a Resource-based Theory Perspective. Journal of Operations Management. vol. 25, no. 6, pp. 1217-1233, 2007.

[5] K. Bennett, Legacy Systems: Coping with Success. IEEE Software. vol. 12, no. 1, pp. 19-23, 1995.

[6] J. Bergqvist and P. Dahlberg, Scalability through Cultivation: Using Co-ordination Theory in Design. Scandinavian Journal of Information Systems. vol. 11, no. 1, pp. 1-18, 1999.

[7] J.M. Bryson, What To Do When Stakeholders Matter: a Guide to Stakeholder Identification and Analysis Techniques. Public Management Review. vol. 6, no. 1, pp. 21-53, 2004.

[8] H. Charles and H.C.J. Godfray, Challenges for Taxonomy. Nature. vol. 417, no. 6884, pp. 17-19, 2002.

[9] D. Chen, G. Doumeingts, and F. Vernadat, Architectures for Enterprise Integration and Interoperability: Past, Present and Future. Computers in Industry. vol. 59, no. pp. 647-659, 2008.

[10] F. Chen, Z. Drezner, J.K. Ryan, and D. Simchi-Levi, Quantifying the Bullwhip Effect in a Simple Supply Chain: the Impact of Forecasting, Lead Times, and Information. Management Science. vol. 46, no. 3, pp. 436-443, 2000.

[11] K. Cool and J. Henderson, Power and Firm Profitability in Supply Chains: French Manufacturing Industry in 1993. Strategic Management Journal. vol. 19, no. 10, pp. 909-926, 1998.

[12] T.H. Davenport and D.B. Stoddard, Reengineering: Business Change of Mythic Proportions? Management Information Systems Quarterly. vol. 18, no. 2, pp. 121-128, 1994.

[13] F.D. Davis, Perceived Usefulness, Perceived Ease of Use, and User Acceptance of Information Technology. Management Information Systems Quarterly. vol. 13, no. 3, pp. 319-339, 1989.

[14] R. Drazin and A.H. Van de Ven, Alternative Forms of Fit in Contingency Theory. Administrative Science Quarterly. vol. 30, no. 4, pp. 514-539, 1985.

[15] P.F. Drucker, Management: Tasks, Responsibilities, Practices. New York: Truman Talley / E.P. Dutton, 1986.

[16] V. Francis, Supply Chain Visibility: Lost in Translation? Supply Chain Management. vol. 13, no. 3, pp. 180-184, 2008.

[17] R.E. Freeman, Strategic Management: a Stakeholder Approach. New York: Cambridge University Press, 2010.

[18] T.N. Garavan, Global Talent Management in Science-based Firms: an Exploratory Investigation of the Pharmaceutical Industry during the Global Downturn. International Journal of Human Resource Management. vol. 23, no. 12, pp. 2428-2449, 2012.

[19] S. Gregor, The Nature of Theory in Information Systems. MIS Quarterly: Management Information Systems. vol. 30, no. 3, pp. 611-642, 2006.

[20] S. Gregor and D. Jones, The Anatomy of a Design Theory. Journal of the Association of Information Systems. vol. 8, no. 5, pp. 312-335, 2007. 
[21] M. Grisot, O. Hanseth, and A.A. Thorseng, Innovation Of, In, On Infrastructures: Articulating the Role of Architecture in Information Infrastructure Evolution. Journal of the Association of Information Systems. vol. 15, no. Special Issue, pp. 197-219, 2014.

[22] O. Hanseth and K. Lyytinen, Design Theory for Dynamic Complexity in Information Infrastructures: the Case of Building Internet. Journal of Information Technology. vol. 25, no. 1, pp. 1-19, 2010.

[23] I. Harpaz and I. Meshoulam, Intraorganizational Power in High Technology Organizations. Journal of High Technology Management Research. vol. 8, no. 1, pp. 107-128, 1997.

[24] S. Henningsson, U. Gal, N. Bjørn-Andersen, and Y. Tan, The Next Generation Information Infrastructure for International Trade. Journal of Theoretical and Applied Electronic Commerce Research. vol. 6, no. 1, pp. 1-15, 2011.

[25] D. Hesketh, Weaknesses in the Supply Chain: Who Packed the Box? World Customs Journal. vol. 4, no. 2, pp. 3-20, 2010.

[26] M. Holweg, S. Disney, J. Holmström, and J. Småros, Supply Chain Collaboration: Making Sense of the Strategy Continuum. European Management Journal. vol. 23, no. 2, pp. 170-181, 2005.

[27] M. Janssen, A.E. Chun, and J.R. Gil-Garcia, Building the Next Generation of Digital Government Infrastructures. Government Information Quarterly. vol. 26, no. pp. 233-237, 2009.

[28] U. Jüttner and S. Maklan, Supply Chain Resilience in the Global Financial Crisis: an Empirical Study. Supply Chain Management. vol. 16, no. 4, pp. 246-259, 2011.

[29] A.J. Klievink, E. Van Stijn, D. Hesketh, H. Aldewereld, S. Overbeek, F. Heijman, and Y. Tan, Enhancing Visibility in International Supply Chains: the Data Pipeline Concept. International Journal of Electronic Government Research. vol. 8, no. 4, pp. 14-33, 2012.

[30] A.J. Knol, M. Janssen, and H.G. Sol, A Decision Enhancement Service for Stakeholder Analysis to Achieve Transformations in the Public Sector, in The Fourty-Eigth Annual Hawaii International Conference on System Sciences (HICSS), IEEE Computer Society Press. p. 2466-2475, 2015.

[31] A.J. Knol, A.J. Klievink, and Y. Tan, Data Sharing Issues and Potential Solutions for Adoption of Information Infrastructures: Evidence from a Data Pipeline Project in the Global Supply Chain over Sea, in The 27th Bled eConference (BLED), A. Pucihar, et al., Editors, Bled eCommerce Conference: Bled. p. 267-278, 2014

[32] H.L. Lee, V. Padmanabhan, and S. Whang, Information Distortion in a Supply Chain: the Bullwhip Effect. Management Science. vol. 43, no. 4, pp. 546-558, 1997

[33] M.L. Markus and N.B. Quang, Going Concerns: The Governance of Interorganizational Coordination Hubs. Journal of Management Information Systems. vol. 28, no. 4, pp. 163-197, 2012.

[34] A. Matopoulos, M. Vlachopoulou, V. Manthou, and B. Manos, A Conceptual Framework for Supply Chain Collaboration: Empirical Evidence from the Agri-Food Industry. Supply Chain Management: An International Journal. vol. 12, no. 3, pp. 177-186, 2007.

[35] S. Min, A.S. Roath, P.J. Daugherty, S.E. Genchev, H. Chen, and A.D. Arndt, Supply Chain Collaboration: What's Happening? The International Journal of Logistics Management. vol. 16, no. 2, pp. 237-256, 2005

[36] E. Monteiro, N. Pollock, and R. Williams, Innovation in Information Infrastructures: Introduction to the Special Issue. Journal of the Association of Information Systems. vol. 15, no. Special Issue, pp. i-x, 2014

[37] S. Overbeek, M. Janssen, and Y. Tan, An Event-driven Architecture for Integrating Information, Processes and Services in a Plastic Toys Supply Chain. International Journal of Cooperative Information Systems. vol. 21, no. 4, pp. 343-381, 2012.

[38] G.S.C. Pan, Information Systems Project Abandonment: a Stakeholder Analysis. International Journal of Information Management. vol. 25, no. 2, pp. 173-184, 2005.

[39] J. Pfeffer and G. Salancik, The External Control of Organizations: a Resource Dependence Perspective. New York: Harper and Row, 1978.

[40] D. Robey, G. Im, and J.D. Wareham, Theoretical Foundations of Empirical Research on Interorganizational Systems: Assessing Past Contributions and Guiding Future Directions. Journal of the Association of Information Systems. vol. 9, no. 9, pp. 497-518, 2008.

[41] J. Rowley, E-government Stakeholders - Who Are They and What Do They Want? International Journal of Information Management. vol. 31, no. 1, pp. 53-62, 2011

[42] R.E. Sabath and J. Fontanella, The Unfulfilled Promise of Supply Chain Collaboration. Supply Chain Management Review. vol. 6, no. 4, pp. 24-29, 2002.

[43] H.J. Scholl, Applying Stakeholder Theory to E-government, in Towards the E-Society, B. Schmid, K. Stanoevska-Slabeva, and V. Tschammer, Editors, Springer US: Boston, MA. p. 735-747, 2001

[44] T.A. Schwandt, Constructivist, Interpretivist Approaches to Human Inquiry, in Handbook of Qualitative Research, N.K. Denzin and Y.S. Lincoln, Editors, Sage Publications: Thousand Oaks. p. 118-137, 1994

[45] W.R. Scott, Organizations: Rational National and Open Systems. Englewood Cliffs, NJ: Prentice-Hall, 1981.

[46] R.S. Sharma, S. Foo, and M. Morales-Arroyo, Developing Corporate Taxonomies for Knowledge Auditability: a Framework for Good Practices. Knowledge Organization. vol. 35, no. 1, pp. 30-46, 2008

[47] U. Soni, V. Jain, and S. Kumar, Measuring Supply Chain Resilience Using a Deterministic Modeling Approach. Computers and Industrial Engineering. vol. 74, no. 1, pp. 11-25, 2014.

[48] Y. Tan, N. Bjørn-Andersen, S. Klein, and B. Rukanova, Accelerating Global Supply Chains with IT-Innovation: ITAIDE Tools and Methods. Berlin Heidelberg: Springer, 2011.

[49] D. Tilson, K. Lyytinen, and C. Sørensen, Digital Infrastructures: the Missing IS Research Agenda. Information Systems Research. vol. 21, no. 4, pp. 748-759, 2010.

[50] D. Ulrich and J.B. Barney, Perspectives in Organizations: Resource Dependence, Efficiency, and Population. The Academy of Management Review. vol. 9, no. 3, pp. 471-481, 1984. 
[51] W.M.P. van der Aalst, A.H.M. ter Hofstede, and M. Weske, Business Process Management: a Survey, in Business Process Management, W.M.P. van der Aalst and M. Weske, Editors, Springer: Berlin Heidelberg. p. 1-12, 2003.

[52] Y. Wand and R.Y. Wang, Anchoring Data Quality Dimensions in Ontological Foundations. Communications of the ACM. vol. 39, no. 1, pp. 86-95, 1996.

[53] O.E. Williamson, The Economics of Organization: the Transaction Cost Approach. American Journal of Sociology. vol. 87, no. 3, pp. 548-577, 1981. 